\title{
elyra
}

\section{Francis Ponge e a escrita em processo}

\section{Danielle Grace de Almeida}

\section{Unicamp}

Resumo: Na poética de Francis Ponge, as coisas são materiais de inspeção que ajudam a compor uma espécie de arqueologia do presente, remontando o que constitui o homem e sua relação com a realidade. Porém, longe de qualquer tentativa de fixação desse mesmo presente, a poesia pongiana, sorte de rascunhos, anotações incompletas, textos inacabados parecem se apresentar para o leitor como um caleidoscópio cujos cacos de cristais e espelhos não cessam de desdobrar novos significados a cada gesto da escrita. O “método" pongiano se revelaria, assim, como processo de investigação do próprio texto (do) mundo, oferecendo-nos suas poesias menos como essência das coisas do que como exploração de seus possíveis significados.

Palavras-chave: Francis Ponge, poesia moderna, rascunhos, processo de escrita

Abstract: In Francis Ponge's poetics, the things are materials that help to compose a kind of archeology of the present, tracing back what constitutes man and his relation to reality. However, far from any attempt to stick to this present moment, Pongian poetry, drafts, incomplete notes, unfinished texts seem to show themselves to the reader as a kaleidoscope which shards of crystals and mirrors do not cease to unfold new meanings to each gesture of the writing. The Pongian "method" would reveal itself as a process of investigation of the text, offering its poetry less as the essence of things than as the exploration of its possible meanings.

Keywords: Francis Ponge, modern poetry, drafts, writing process 
A obra do poeta Francis Ponge inspirou inúmeras reflexões sobre a crise da poesia, anunciada por Mallarmé e recorrente na produção e crítica de poesia desde então. Assim como o autor de "Crise de vers", Ponge vislumbrou uma ruptura estética a se realizar através da língua. Em Structure de la Poésie Moderne, Hugo Friedrich tenta mapear os princípios metodológicos que teriam embasado a poesia depois de Baudelaire, Rimbaud e Mallarmé e arriscando uma primeira definição, afirma que

esses poetas [os ditos modernos] permitem a seus leitores uma experiência que, antes mesmo que eles tomem clara consciência, os conduz para próximo de uma das características essenciais dessa poesia: sua obscuridade fascina o leitor tanto quanto o desconcerta. Sua magia verbal e seu mistério exercem fascinação, embora o entendimento não possa ainda se orientar nela. (Friedrich 1999: 13, 14)

É bem verdade que, a partir de Mallarmé, a poesia moderna é concebida mais como um jogo de manipulação linguística que como um espaço em que significado e significante se conjuguem harmoniosamente. Contudo, em relação a Ponge, a atribuição de tal dicotomia entre obscuridade e clareza de sentido nos exigiria uma análise mais cuidadosa. Jean-Marie Gleize, em "Francis Ponge", chega a afirmar que ele é "decididamente o poeta que, no século XX, mais trouxe (com mais obstinação e acuidade crítica) a suspeita em relação à ideia que nos fazemos da 'poesia'” (Gleize 1999: 15). Essa observação não se encontra, aliás, desvinculada de uma constatação, que é a de uma evidente solidão do poeta no que concerne à produção poética de sua geração (Gleize 2014). Nesse ponto, a crítica pongiana parece estar de acordo, pois que numerosos estudos se empenham em demostrar o quão difícil é ajustar Ponge em uma corrente ou escola poética da história moderna da literatura francesa.

Tendo em vista essa interpretação da crítica, poderíamos nos perguntar se a solidão de Ponge não se explicaria pelo fato de que o poeta almeja, de certo modo, se localizar fora da poesia ou "performatizar" uma saída dela. A escrita de Ponge não se realiza, portanto, sem sinalizar que uma outra modernidade está sendo construída. Como ele diz em Comment une Figue de Paroles et Pourquoi [Como um Figo de Palavras e Por que], de 1977: "Je ne sais pas trop ce qu'est la poésie, mais par contre assez bien ce que c'est une figue" [“Eu não sei bem o que é a poesia, mas por outro lado sei bem o que é um figo"] (Ponge 2002: 781). Por 
isso, os textos inacabados de Ponge, espécie de notas suspensas, representam, a meu ver, uma das maiores encenações do projeto de modernidade do poeta, pois evidenciam a todo o momento a impossibilidade de conceber a escrita poética senão no decorrer de um processo em andamento. O texto, nesse caso, não se apresenta como uma composição fechada harmonizando a forma poética e o sentido, nem bem ao modo dos modernos de início do século XX em que se ambiciona a destruição formal do poema. Em Ponge, palavras e coisas são pretextos para uma interferência moral e estética a se realizar na e pela língua.

Nas versões inacabadas e fragmentadas do poema sobre o figo, no livro citado há pouco, uma série de anotações a respeito da fruta aparece no decorrer das páginas. A cada etapa inconclusa, o poema retorna ao ponto principal anterior para daí acrescentar um novo aspecto que acaba por contorcer a coisa em um sentido novo, uma versão outra de si própria. Gérard Farasse, em L'Âne Musicien [O Asno Musicista], chama atenção para o fato de que, de forma geral, o rascunho, por não ter sido oferecido ao público pelo autor, é um tipo de acesso interdito ao texto, à intimidade do trabalho do escritor, que não o considerou primeiramente parte de sua obra. (Farasse 1996) Em Ponge, no entanto, o rascunho ganharia outra dimensão, uma vez que o autor deseja exibi-lo, não como um anexo da obra, mas como a própria obra. Além disso, Farasse assinala que, para o poeta, não se trata de preferir uma expressão em detrimento de outra já utilizada. As correções se tornariam, então, etapas expostas do trabalho que nunca desaparecem do poema. O crítico observa que Ponge "não apaga, ele conserva [a opção anterior], tratando a escrita como uma palavra à qual só é possível voltar acrescentando algo". (Farasse 1996: 89)

Em entrevista a Jean Ristat, em 1978, Ponge fala sobre esses escritos e explica que "dans ce qu'on peut appeler un brouillon, un nouveau brouillon, chaque fois je vais de nouveau au cœur de ma préoccupation, en plein cœur, et non à quelques détails" ["no que se pode chamar de rascunho, um novo rascunho, a cada vez, eu vou de novo no cerne da minha preocupação, no coração dela, e não em alguns detalhes"] (Ponge 2002: 1424-1425). E referindo-se às partes inacabadas que os rascunhos expõem, acrescenta,

... quand j'ai l'impression que je déraille ou que je sors vraiment du sujet, eh bien, à ce moment-là je m’arrête. C'est pour ça qu'il y a des pages qui s'arrêtent comme ça, de façon parfaitement abrupte. Et puis le lendemain, je repars en plein dans le truc ". (Ponge 2002: 1424-1425) 
[...quando eu tenho a impressão de ter desviado ou de que saí realmente do assunto é aí, nesse momento, que eu paro. É por isso que há páginas que se acabam assim, de modo perfeitamente abrupto. E então, no dia seguinte, eu retomo no cerne da coisa. ]

O resultado desse método de rascunho é muitas vezes uma prosa separada por asteriscos, datas e horas, como registros de um trabalho em andamento que acabam por insinuar um afastamento das concepções tradicionais da poesia, ou seja, do procedimento do verso e da rima. Essa tensão é declarada pelo poeta em outro momento, em Proêmes9/ Proemas, de 1948, quando explica suas pretensões da seguinte forma: “je voudrais écrire une sorte de De natura rerum ${ }^{1}$. On voit bien la différence avec les poètes contemporains : ce ne sont pas de poèmes que je veux composer, mais une seule cosmogonie." ["gostaria de escrever um tipo de De natura rerum. Bem se vê a diferença com os poetas contemporâneos: não são poemas que quero compor, mas uma única cosmogonia"] (Ponge 1999: 204).

É preciso pensar essa declaração de Ponge em relação ao que procurei apontar como seu gesto de "performatizar" uma saída para fora da poesia. Isso nos permite realizar um diálogo com as reflexões de Jonathan Culler, em "Philosophie et littérature: les fortunes du performatif" ["Filosofia e literatura: as fortunas do perfomativo"] sobre a noção de performance, colocando-as em articulação com a escrita processual do poeta. Para o crítico americano, a literatura se apropriaria da noção de performativo em Austin para considerar a "enunciação literária" como aquela que criaria, "ela também, o estado de coisas ao qual ela se refere, sob diferentes formas" (Culler 2006: 86). No entanto, levando-se em consideração o que o próprio Culler diz a respeito das diferentes apropriações do conceito de Austin, é necessário ir além da escolha de uma só chave de compreensão. Trata-se, então, no que tange à questão do processo em Ponge, de estabelecer um diálogo entre o que Culler nos diz do enunciado literário com suas próprias reflexões sobre o modo como Judith Butler opera o performativo em seus deslocamentos críticos. Nas palavras de Culler, Butler ajudaria "a conceber essa performatividade inabitual, que questiona repetindo os atos fundadores, em uma repetição que pode ter um valor crítico, movimentando e alterando as formas que ela repete." (Culler 2006: 98) Os rascunhos de Ponge operariam, portanto, ao modo de uma 
enunciação iterativa enquanto performance que não cessaria de reiterar certo lugar: "não são poemas". Porém, pela própria força de sua repetição crítica que se dá a ver como processo, essa mesma performance parece se abrir sobre a possibilidade de emergência de uma nova poesia.

Sendo assim, como forma de abordar o desafio performático colocado em cena por Ponge, considerarei a seguinte hipótese: a esses "não poemas" que ele compôs nesses livros, indicando o que seriam tipos específicos de textos, seus rascunhos, chamarei de notas indiciárias. De suas realizações - ao mesmo tempo enunciativas e pragmáticas dependeriam o retorno crítico à petição de princípio "não são poemas o que quero compor", possibilitando, assim, o surgimento de uma nova forma de poesia. Nestas notas, a cada parte, a tentativa de uma definição da coisa, - mesa, sabão, prado, figo -, parece possível somente na remissão a outro objeto, a outro nome, intermediado por algum rastro ou sinais aos quais os olhos do poeta parecem sempre atentos para observar e interrogar. Nesse ritmo, o poeta construiria uma espécie de anotações investigativas em que seguir indícios implicaria necessariamente na fabricação de novas pistas. Assim, um signo solicita outro dando partida a uma engrenagem em constante funcionamento.

A atitude de Ponge de conservar seus poemas em fase de "imperfeição" pode ser interpretada também como um de seus métodos criativos. Em La Fabrique du Pré [A Fábrica do Prado], de 1971, as notas apresentam observações e lembretes sobre o que deve ser feito no momento de retomada da escrita. Nesse livro, como explica o próprio autor em uma espécie de mini-prefácio, as partes do texto são agrupadas como se o poeta desejasse "mettre sur la table les états successifs de [s]on travail" d'écriture à propos de telle ou telle émotion" ["pôr sobre a mesa os estados sucessíveis de [s]eu trabalho de escrita a propósito de uma ou outra emoção."] (Ponge 2002: 425). Dessa forma, é que os rascunhos, que nunca desembocam em uma versão definitiva do poema, performariam ao mesmo tempo sua impossibilidade e realização enquanto poesia. Ou seja, por meio desse procedimento em que Ponge encena sua suspeita sobre o que seja a poesia é que a solução acaba por se colocar por duas vias aparentemente contraditórias, mas no fundo complementares: a ideia de que a poesia está sempre em processo e a enunciação performativa de sua própria impossibilidade. 
Mas de quais mecanismos, exatamente, as performances executadas pelos rascunhos se serviriam? Dessa resposta depende, obviamente, a própria singularidade da poesia de Ponge. Seguindo os próprios sinais de sua obra, com as inúmeras referências aos poetas clássicos e autores antigos, proponho lermos essas notas indiciárias à luz de uma noção cujos fundamentos remontam ao século XVII: a de serendipidade. Segundo Sylvie Catellin, no artigo "Sérendipité et Réflexivité" ["Serendipidade e Reflexividade"], esta palavra foi definida pela primeira vez em 1754, pelo escritor inglês Horace Wapole, que o considerou como o fato de "descobrir, por acaso e sagacidade, coisas que não se procurava." (Wapole apud Catellin 2012: 74). Wapole, por sua vez, teria se inspirado em um conto persa, "Viagens e aventuras dos três príncipes de Serendip", que, segundo Catellin, seria a "história de três irmãos que sabem descrever um animal que nunca viram" (Catellin 2012: 74). A mesma história é mais ou menos retomada em Zadig (1747), de Voltaire, em que o protagonista descreve com perfeição os animais procurados pelo rei e a rainha de Seredip apenas observando as pistas deixadas pelos mesmos.

A intitulação por notas indiciárias desses textos em que a ideia de rastro está presente exige também um diálogo com as questões desenvolvidas por Carlo Ginzburg, em "Sinais, raízes de um paradigma indiciário". Ao explicar o método do escritor italiano Mancini para distinguir a pintura original da falsificada, Ginzburg narra a história de

um médico célebre pelos seus fulminantes diagnósticos - um homem que, encontrando um doente, com um rápido olhar (...) adivinhava que fim aquela doença viria a ter. Será permitido, a esse ponto, ver no olho, clínico-olho do conhecedor, algo mais que uma simples coincidência. (Ginzburg 1990: 159)

É mais ou menos de modo acidental que Ponge percebe certos indícios em seus objetos, mas é sobretudo, penso, por um ímpeto de busca obsessiva e atenção aos sinais que, em La Table / A Mesa, de 1991, ele passa do objeto mesa para o console que a sustenta; deste para a palavra consolação, que o conduz às "Consolations de Boèce" [“Consolações de Boécio"] ${ }^{3}$, ou seja, uma obra escrita, que se realiza sobre a mesa e que é a consolação do escritor. Ao relacionar tão intimamente mesa (objeto) e consolação (palavra), o poeta se depara com a prova, aquilo que o conduziu a escrever sobre a mesa: o verbo "consolide"/ "consolida". Isto é, consolidar a escrita, uma obra como fez Boécio antes de sua 
morte ${ }^{4}$, sobre o que é "solide" [sólido], a matéria, que, neste caso, é a madeira, mas também a matéria verbal, o que constitui a linguagem humana. (Ponge 2002: 940-941). Como podemos ver nesse exemplo de La Table, as notas curtas e inacabadas, separadas por asteriscos e entremeadas de repetições desembocam em pequenas transformações na ortografia das palavras e, por conseguinte, no sentido, como sinais que o poeta vai seguindo e desvelando para o leitor. Como é possível observar neste outro trecho:

Notes sur la TABLE

La table vient se placer sous mon coude

La table souvient à mon coude

Tandis qu'il me souvient de la table (de la notion de la table), quelque table vient sous mon coude. (Ponge 2002: 915)

[Notas sobre a MESA

A mesa vem se pôr sob meu cotovelo

A mesa subvém a meu cotovelo

Enquanto me advém a tábula (a noção de tábula), alguma mesa vem sob meu cotovelo.]

Nesse fragmento, o verbo venir ("vient") parece sugerir ao escritor o seu derivado souvenir ("souvient"). Na linha seguinte, este é retomado em sua forma reflexiva cujo sentido é outro. Esse desdobramento parece a prova e um trunfo para o poeta, que a grifa em itálico. Ao mesmo tempo, a sequência de associações feitas a partir de sons e sentidos conduz o leitor à outra atmosfera em relação a coisa: agora a mesa é mais o símbolo do processo de escrita e do legado desta atividade do que o objeto em si, e todo o poema se renova a partir desse dado. Há também, na condução de suas notas, os vestígios de um comprometimento moral: o corpo lembra ao poeta o sentido da mesa e a matéria do corpo se une à consistência material da coisa: "Tandis qu'il me souvient de la table (de la notion de la table), quelque table vient sous mon coude." (Ponge 2002: 915)

As notas indiciárias permitem a sustentação de duas interpretações que sendo opostas e complementares ao mesmo tempo evidenciam a novidade do método pongiano. A 
primeira, como já apontado anteriormente, expõe os pressupostos de uma poesia moderna, inacabada, que evidencia a impossibilidade de se realizar senão através da extrapolação da própria linguagem poética. É pela forma que o poeta dramatiza performatiza a crise da poesia, mostrando que a saída, e a não-saída, só pode se realizar na manipulação da matéria verbal e de sua experimentação contínua. Michel Deguy, em La Poésie n'est pas seule [A Poesia não está só], ao falar desse momento de crise protagonizado pela poesia moderna e contemporânea, afirma que "a saída é e não-é a saída", pois que "há somente impasses, ruas, aporias". Sendo assim, "qual pode ser então o caminho que é e não é o caminho, qual é a saída se não há saída? A saída, o encaminhar-se para a saída, o caminhar é então o de passar de um impasse a outro" (Deguy 1988: 169). Dizendo de outro modo e em relação ao contexto pongiano, as notas indiciárias, com todas as pistas de continuidade, os indicativos de incompletude, se realizam nesse movimento de passar do indicativo de saída do objeto para a linguagem, e da palavra para a coisa. O poeta segue como se desejasse mostrar que a saída está na não-saída da matéria verbal, a qual, por sua vez, é constantemente tensionada pela sua própria relação com o mundo. É nesse sentido que Ponge constrói um trabalho minucioso de investigação da coisa, de dispô-la em sua mesa, como ele diz em "L'œillet" [“O cravo"], poema de La Rage de l'Expression [A Raiva da Expressão], de 1952:

\footnotetext{
Je n'aurai de cesse avant d'avoir assemblé quelques mots à la lecture ou l'audition desquels l'on doive s'écrier nécessairement : c'est de quelque chose comme un œillet qu'il s'agit.
}

Est-ce là poésie ? Je n'en sais rien, et peu importe. Pour moi c'est un besoin, un engagement, une colère, une affaire d'amour-propre et voilà tout. (Ponge 1999: 356)

[Eu não irei descansar enquanto não tiver reunido algumas palavras das quais a leitura e a audição nos faça necessariamente exclamar: é de algo como um cravo que se trata.

É isso a poesia? Não sei e pouco importa. Para mim é uma necessidade, um engajamento, uma fúria, um caso de amor próprio, enfim, tudo.]

Pode-se ainda vislumbrar outra chave de compreensão para esses escritos de Ponge, o que nos obriga mais uma vez a voltar o olhar em direção ao passado como pistas deixadas pelo poeta em sua obra. Comecemos, então, por indagar de que modo a novidade do 
método pongiano poderia encontrar eco no modelo anacrônico do fabulista, do qual La Fontaine permanece a figura mais emblemática. Esse diálogo que Ponge reata repetidamente ao longo de sua obra desvelaria, primeiramente, uma noção própria de responsabilidade, da que o poeta parece se incumbir, deixando suas lições como quem entrega um legado poético para a posteridade. Entre poesia e fábula, pode-se entrever o nascimento e a estruturação de um estilo, agindo sobre o modo como a realidade é percebida através da linguagem. Em relação ao que, em La Fontaine, atrai Ponge, acredito, como Bernard Veck em Le Parti Pris des Choses de Francis Ponge [O Partido das Coisas de Francis Ponge], que é

a densidade das fórmulas que ele [La Fontaine] propõe, e que são impostas à língua comum (por sua forma) como provérbios contribuindo por um lado a conferir ao idioma seu saber particular, sua qualidade diferencial, e, por outro, ao autor, com o anonimato (já que sua palavra se funda na língua), um poder e uma sobrevida que excedem consideravelmente os de sua obra enquanto tal, e que o identificam à originalidade linguística de toda uma coletividade. (Veck 1994: 65)

Ora, para Ponge, trata-se mesmo de se fundir na "língua comum" transbordando o papel de escritor para além de um manobrista ardiloso do idioma. Isso significa um trabalho sobre a realidade linguística, de incrustação e sedimentação de novos sentidos. Tal como uma pedra - ou um "Galet" ["Seixo"], para citarmos um dos poemas-estudo de Le Parti Pris des Choses [O Partido das Coisas], de 1942 - que vai sendo esculpida pela natureza, a língua recebe traços, sinais, vestígios de sua apropriação por "toda uma coletividade". Para desarticular e rearticular esses mecanismos, é preciso um trabalho meticuloso com as peças que os compõem.

Esse é um aspecto da modernidade pongiana em que é preciso pensar, pois, expondo uma linguagem poética que se pretenda a mais bem trabalhada em todos os seus ângulos, não se rende ao mesmo tempo a um hermetismo poético ou, tampouco, aos sentidos viciados da língua. Para o escritor, ao que tudo indica, todo esse trabalho contribuiria para a desconstrução do olhar do homem sobre as coisas e a linguagem. Eis uma parte importante dessa performance em que o papel do poeta e da poesia vão sendo reajustados. Em entrevista com Sollers, em 1970, Ponge explica que é nesse sentido que o poeta "travaill[e] 
pour changer les figures qui permettent de se voir et se comprendre dans le monde" ["trabalha para mudar as figuras que permitem nos vermos e nos compreendermos no mundo"] ${ }^{5}$ (Ponge 1970: 71). É o lado mais coletivo da linguagem que Ponge parece realçar, como assinala também Georges Mounin, em Sept Poètes et le Langage [Sete Poetas e a Linguagem]. Segundo Mounin, Ponge "não faz da linguagem (da escrita!) um mundo autossuficiente, gratuito, um além-mundo, um outro mundo. O uso estético e individual da linguagem por alguns acaba sempre por aumentar o uso social da mesma linguagem para todos" (Mounin 1992: 80).

Para entendermos de que modo esse "uso estético e individual da linguagem" se torna o "uso social" "para todos" é preciso pensar em Ponge tal qual um fabulista que se dirige a todos os que falam e que estão implicados na e pela língua. Eis um ponto de diferença que a modernidade de Ponge traz à sua geração e que se faz necessário examinar de maneira mais aprofundada. Ele não pretendia ser considerado um poeta obscuro, adjetivo que se convencionou atribuir, como vimos, ao próprio Mallarmé e a uma certa definição de modernidade que se seguiu a partir dele. É esse aspecto, aliás, que aproximaria Ponge também de alguns poetas clássicos. Podemos constatar minimamente essa relação em Pour un Malherbe [Para um Malherbe], de 1951, em que, se referindo a Malherbe, poeta do século XVII, Ponge acabar por explicar a sua própria perspectiva poética:

Tout me plaît chez Malherbe, dont Baudelaire seul approche parfois, et La Fontaine, dans leurs meilleurs moments.

$[\ldots]$

C'est la maison où je veux demeurer.

La parole (chaque parole) y a sa dimension juste. (Ponge 2002: 7)

[Tudo me agrada em Malherbe, do qual somente Baudelaire se aproxima às vezes, e La Fontaine, nos seus melhores momentos.

$[\ldots]$

É a casa onde quero permanecer

Lá, a palavra (cada palavra) tem sua dimensão justa. ]

Podemos ver neste fragmento o que the pareceu importante nesses autores. A simplicidade das formas aliada, ao mesmo tempo, à "sa dimension juste". Tudo compondo 
uma acessibilidade ideal do escritor com o seu público. Apontando também para a materialidade da língua, da "parole", pronunciável, repetível, gerando fórmulas circuláveis como as de uma fábula que se tornam ditos populares. Todavia, a admiração pelos mestres não se revertia, para o poeta, em repetição do que foi feito, como ele mesmo testemunha em Le Savon / O Sabão, de 1967: "Chaque fois que je relisais les maîtres, aussi bien les modernes que les anciens, l'enthousiasme et l'admiration me saisissaient, mais je m'écriais intérieurement dans le même moment : 'Fait!' (et donc, à ne pas refaire)" ["Cada vez que eu relia os mestres, tanto os modernos quanto os antigos, o entusiasmo e a admiração me tomavam, mas no mesmo momento eu clamava no meu interior: 'Feito!' (logo, não refazer)"] (Ponge 2002: 410).

É nessa medida que a repetição aparece ligada a uma ideia de retomada crítica, e isto tanto em relação a esses autores quanto ao processo de seus próprios escritos e o modo como evocam toda uma história dos usos da língua e do fazer poético. Repetir não para ecoar o mesmo, mas para abrir os espaços de possibilidade em que algo novo - uma nova poesia? - possa emergir, pois, como diz Culler em seu diálogo com Butler, "uma obra é bem sucedida, torna-se um evento, pela repetição massiva que retoma as normas e pode acabar por mudar as coisas." (Culler 2006:98) As notas indiciárias, performatizando o lado ad(verso) e processual do poema, indicam que o próprio sentido que se atribui à poesia deve ser questionado, apontando assim ao mesmo tempo para sua impossibilidade e para os indícios de que outros paradigmas estão por ser construídos.

\section{Notas}

\footnotetext{
${ }^{1}$ A referência aqui é ao longo poema de Lucrécio escrito em língua latina, em que este retoma a doutrina de Epícuro.

${ }^{2}$ Grifos do autor.

${ }^{3}$ Referência à obra A Consolação da Filosofia, escrito por Boécio a espera de sua execução pelo rei Teodorico.

${ }^{4}$ La Table é uma publicação póstuma de Ponge que morre em 1983.

${ }^{5}$ Grifo do autor.
} 


\section{Bibliografia}

Catellin, Sylvie (2012), "Sérendipité et réflexivité", Alliage, n. 70,

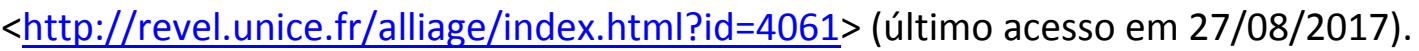

Culler, Jonathan, "Philosophie et littérature: les fortunes du performatif". Littérature, 2006/4, n. 144, 81-100.

Deguy, Michel (1988), La poésie n'est pas seule, Paris, Seuil.

Farasse, Gérard (1996), L'âne musicien : sur Francis Ponge, Paris, Gallimard.

Friedrich, Hugo (1999), Structure de la poésie moderne, tradução de Michel-François Demet, Paris, Le livre de Poche.

Ginzburg, Carlo (1990), "Sinais: raízes de um paradigma indiciário", in Mitos, emblemas, sinais: Morfologia e História, São Paulo, Companhia das Letras.

Gleize, Jean-Marie (org.) (1999), Francis Ponge, Les cahiers de I'Herne, Paris, L'Herne/ Fayard.

Gleize, Jean-Marie (2014), "Ponge ?”, in Sorties, Paris, Broché / Questions théoriques.

Mounin, Georges (1992), "Francis Ponge et le langage", in Sept poètes et le langage, Paris, Gallimard.

Ponge, Francis (1970), Entretiens de Francis Ponge avec Philippe Sollers, Paris, Gallimard/Seuil.

-- (1999), CEuvres Complètes I, Bibliothèque de le Pléiade, Paris, Gallimard.

-- (2002), CEuvres Complètes II, Bibliothèque de le Pléiade, Paris, Gallimard.

Veck, Bernard (1994), Le Parti pris des choses de Francis Ponge, Paris, Bertrand Lacoste. 
Danielle Grace de Almeida é doutora pela Universidade Federal do Rio de Janeiro onde desenvolveu uma tese sobre Francis Ponge e a poesia francesa (2015), Danielle Grace realiza atualmente uma pesquisa de Pós-doutorado na Universidade Estadual de Campinas (Unicamp) sobre a noção de modernidade que permeia a poesia francesa moderna e contemporânea. 